\title{
The Effects of Extensive Reading on English Vocabulary Learning: A Meta-analysis
}

\author{
Jiren Liu ${ }^{1} \&$ Jianying Zhang ${ }^{1}$ \\ ${ }^{1}$ English Department, Dalian Neusoft University of Information, No. 8 Software Park Road, Dalian, China \\ Correspondence: Jianying Zhang, English Department, Dalian Neusoft University of Information, No. 8 \\ Software Park Road, Dalian, China. E-mail: zhangjianying@neusoft.edu.cn
}

Received: April 1, 2018 Accepted: May 6, 2018 Online Published: May 8, 2018

doi: 10.5539/elt.v11n6p1 URL: http://doi.org/10.5539/elt.v11n6p1

\begin{abstract}
Extensive reading has been continuously studied as a promising instructional method for improving students' language proficiency, including reading proficiency, vocabulary acquisition, and grammar awareness. The present study is a meta-analysis, which synthesized the data of 21 empirical studies $(\mathrm{N}=1268)$. It was designed to explore whether extensive reading instruction was effective in improving students' vocabulary acquisition, and if so, how the effectiveness varied in terms of the instruction length and teaching methods. Stata 14.0 was utilized to calculate the collected data. The results revealed that: (1) extensive reading has a significant effect on English vocabulary learning; (2) one semester (less than three months) is the most appropriate length of extensive reading instruction for vocabulary learning; (3) Graded Readers, comprehension questions and vocabulary exercise play significant roles as reading materials and education methods in promoting the vocabulary learning of EFL learners.
\end{abstract}

Keywords: meta-analysis, extensive reading, vocabulary, effectiveness, EFL

\section{Introduction}

An increasing number of empirical studies have been conducted to examine the effectiveness of extensive reading all over the world in the past decades (e.g., Lee, 2007; Kweon \& Kim, 2008; Cha, 2009; Yamashita \& Kan, 2010; Soltani, 2011; Tiryaki \& Tütüniş, 2012; Chang, 2013; Hamed, 2014; Webb \& Anna, 2015; Ismael, 2017; Suk, 2017; Tabata-Sandom, 2017). However, the research limitation of each independent study, such as relatively short duration of the treatment, small sample size and the lack of replication, may cause difficulty for researchers and English teachers to determine whether extensive reading is universally effective, how it affects the English vocabulary acquisition specifically, and how reliable the outcomes of educational treatments are. This study aims at adopting a meta-analysis to investigate the overall effectiveness of extensive reading on vocabulary learning in EFL environment. Besides the examination of the overall effectiveness of extensive reading on vocabulary learning, it also sheds light on the specific treatment in extensive reading instruction including reading materials and teaching methods. In this study, researchers and teachers who concern extensive reading may find new research directions and be inspired to design more effective extensive reading instruction.

According to Glass (1976), meta-analysis is "the statistical analysis of a large collection of analysis results from individual studies for the purpose of integrating the findings" (p. 3). A meta-analysis can be used to confirm the effectiveness and provide greater insight into a treatment based on the large size and better quality of primary studies.

But that is not to say meta-analysis has no drawbacks. One of its prominent problems is publication bias. Publication bias happens when the data of published literature are exclusively synthesized, which is actually unrepresentative of the population of complete studies (Rothstein et al., 2006). To deal with the publication bias, the data from both published and unpublished studies should be employed in the meta-analysis and a sensitivity analysis is always necessary to investigate the publication bias. Additionally, before aggregating studies of different research quality, it is suggested that strict selection criteria should be employed to include the studies that are qualified. 


\section{Literature Review}

\subsection{Extensive Reading and Vocabulary Learning}

\subsubsection{Extensive Reading}

Extensive reading is a type of reading instruction providing a large number of reading materials to learners independently. Students are required to read extensively for general meaning, information, and pleasure (Day, 2004). Through extensive reading, learners can develop good reading habits, build up vocabulary knowledge and enhance positive reading attitudes. In particular, it is believed that learners may encounter more unknown words when reading independently, which brings opportunities to infer the unknown words in specific contexts and thus learn their meanings (Krashen, 1989). Although the mechanism is commonly accepted to be true, as Cobb (2007) states, it is still disputable whether extensive reading is important. So far, studies concerning extensive reading vary in terms of different study focus, including reading attitude (e.g., Chin-Neng, 2013), reading comprehension (e.g., Wijaya, 2013; Rezaee, 2011; Lin, 2010), reading speed (e.g., Al-Homoud, 2012; Beglar, 2012), grammar (e.g., Rodrigo, 2004) and vocabulary acquisition (e.g., Tan, 2016; Waring, 2003) etc.

Compared with extensive reading, intensive reading requires students to read short texts, obtain detailed meaning with close guidance from the teacher so as to acquire the knowledge of vocabulary and grammar, and develop some reading skills such as identifying main ideas and recognizing text connectors (Hong, 2014). Palmer defines it as "take a text, study it line by line, referring at every moment to our dictionary and our grammar, comparing, analyzing, translating, and retaining every expression that it contains" (1964, p. 111).

\subsubsection{Vocabulary Learning}

Vocabulary refers to the knowledge of words and word meanings. It is suggested that "teaching vocabulary will not guarantee success in reading, just as learning to read words will not guarantee success in reading. However, lacking either adequate word identification skills or adequate vocabulary will ensure failure" (Biemiller, 2005). According to National Reading Panel's synthesis of vocabulary research, vocabulary instructions were suggested to:

- be direct for a specific text (Nagy \& Judith, 2000).

- $\quad$ increase the exposures to vocabulary items repeatedly (Stahl, 2005).

- cover vocabulary words that the learners will find useful in many contexts.

- restructure vocabulary tasks as necessary.

- entails active engagement which goes beyond definitional knowledge so that vocabulary learning is effective.

- use computer technology effectively to help teach vocabulary.

- cover multiple vocabulary instruction methods, which may result in optimal learning (NICHD, 2000).

\subsection{Previous Practice of Meta-Analysis on the Effectiveness of Extensive Reading}

In recent years, meta-analysis has been utilized more frequently than ever before in the field of second language acquisition. Nakanishi (2015) conducted a meta-analysis to examine the overall effectiveness of extensive reading on comprehensive language proficiency. To the authors' knowledge, however, few meta-analysis studies exclusively focused on the examination of extensive reading's effects on vocabulary acquisition. In consideration of the shortcomings of empirical studies and insufficiency of meta-analysis concerning the extensive reading's effects on English vocabulary acquisition, the primary purpose of this study is to synthesize the findings of studies on the extensive reading's effects on English vocabulary learning so as to draw more reliable conclusions regarding extensive reading's overall strength and the identification of the influencing variables.

In addition, the major difference between this study and Nakanishi's (2015) lies on the study interest. Nakanishi studied the overall effect of extensive reading on different language proficiencies, including reading speed, reading comprehension, vocabulary and grammar; while the present study exclusively focuses on one of the specific aspects of language proficiency, vocabulary learning, and conducts detailed exploration on the specific treatment in the independent studies.

\section{Research Questions}

1) Does extensive reading have positive impact on the English vocabulary acquisition of EFL learners?

2) What is the best length of treatment in extensive reading programs? 
3) What are the most effective reading materials and pedagogical treatment of extensive reading in English language instruction?

\section{Methodology}

\subsection{Data Selection and Inclusion Criteria}

The following databases were used to search articles examined in this current meta-analysis: Google Scholar, the Education Resources Information Center (ERIC), ProQuest and Cambridge Core. As a result, our data were composed of published works of the following 16 journals: Advances in Language and Literary Studies, Applied Linguistics - Global and Local, Brazilian, English Language Teaching Journal (BELT), ELT Research Journal, English Language Teaching, English Teaching, International Journal of English and Education, Language Teaching Research, Malaysian Journal of ELT Research, Mediterranean Journal of Social Sciences, Reading in a Foreign Language, RELC Journal, Studies in Literature and Language, Studies in Second Language Acquisition, The Reading Matrix and Vocabulary Learning and Instruction.

Unpublished studies (two doctoral dissertations) were also included, because the publication bias will occur if all the studies included in a meta-analysis are published.

Three criteria were employed to assess the collected studies from the sources mentioned above.

1) The studies should be empirical, which means experiments concerning the effects of ER on vocabulary acquisition should be conducted.

2) The studies should be published or conducted between 2007 and 2016.

3) Data contained in the studies should be available, e.g. means and standard deviations were presented.

With the criteria given above, 21 studies, asterisked in the References section, were finally included in this meta-analysis, in which 17 have control groups and the remaining 4 have not.

\subsection{Data Coding}

To see the overall and specific effects of different variables, the authors coded all 21 studies and categorized all the study variables into seven: participants, length of instruction, control group, reading materials, treatment, test use and test reliability (see Table 1).

Participants

This moderator will help people to know which age group's vocabulary learning has benefited from extensive reading and how many studies have focused on that age group.

Length of Instruction

As a continuous variable in any extensive reading program, the length of instruction will not only have an impact on the learners' level of vocabulary learning through extensive reading, but also answer the second research question mentioned before how long the best extensive reading treatment period will be. Length of instruction was divided into three dichotomous categories for the majority of the 21 studies.

\section{Control Group}

Given that some extensive reading empirical studies do not have control groups to compare the effects of the treatments, this moderator is crucial for this study to see whether control group bring convenience to divide the overall effects examination into two parts in an obvious way.

\section{Reading Material}

As one of the most engaging factors in extensive reading, reading material will answer the last research question whether reading material is suitable for and widely used in extensive reading studies. As an online platform for students doing extensive reading and related exercise, MoodleReader provides texts from Graded Readers for students to read. Stories included in chapter book are selected from various story books. In this case, MoodleReader and chapter book were categorized to Graded Readers and story books respectively.

\section{Treatment}

As one of the creativities and significances of this meta-analysis, the current study will help readers to find out which method in extensive reading will be the most effective and thus propose pedagogical implications for teachers. Five subfactors, book report, comprehension questions, dictionary usage, vocabulary exercise and vocabulary instruction, are included in the treatment. Vocabulary exercise includes sentence making and vocabulary worksheet. They were designed by the teachers or researchers for the purpose of strengthening 
student's vocabulary learning after class. Vocabulary instruction refers to teachers' direct teaching of unknown or important vocabulary in extensive reading program. In addition, other treatments like MoodleReader and oral rendition of texts have also been reported to be effective in improving vocabulary acquisition. All the variables included in treatment were reported to be directly effective to students' vocabulary acquisition in the target 21 studies.

Test Use

Tests including pre-tests and posttests are exclusively vocabulary tests by which the mean scores and standard deviations were generated and collected. The version of test used in the treatment influences the results of the empirical studies, so the reporting of the test version is important.

Reliability

Whether the used tests are reliable is also essential for any study to report, which will affect the reliability of this meta-analysis.

Table 1. Data coding

\begin{tabular}{ll}
\hline Variables & Codes \\
\hline Participants & 1. Junior high school students \\
& 2. High school students \\
& 3. University students \\
& 4. Adults \\
& 5. Children (elementary school or below) \\
& 1. One semester (less than 3 months) \\
Length of instruction & 2. Two semesters [3 months to 6 months] \\
& 3. One year (6 months, 1 year] \\
& 1. Graded Readers \\
Reading materials & 2. Story books \\
& 3. Reading power \\
1. Book report & 2. Comprehension questions \\
Treatment & 3. Dictionary usage \\
& 4. Vocabulary exercise \\
5. Vocabulary instruction & 6. Others \\
1. None (i.e., pre-post design) & 2. One group \\
3est use & 1. Two groups or more \\
Control group & 2. Parallel version \\
1. Not reported \\
2. Reported (data based on the current study) \\
3. Reported (data cited from the test manual) \\
\hline
\end{tabular}

\subsection{Calculation and Interpretation of Effect Sizes}

Among the 21 original studies, 17 have at least one control group, while the other four only involve experimental groups. Because most of the studies compared two groups, Cohen's $d$ index was used as the standardized effect 
size statistic. The descriptors for magnitudes of d-type effect size are displayed in Table 2 below. The $d$ value from 0.01 to 2.0 were originally proposed by Cohen (1988) and later expanded by Sawilowsky (2009). In terms of the interpretation of effect size, the bigger the $d$ value is, the more parallel in size the effect is (Ellis, 2010).

Table 2. The interpretation of effect sizes

\begin{tabular}{lll}
\hline Effect size & $\boldsymbol{d}$ & Reference \\
\hline Very small & 0.01 & Sawilowsky, 2009 \\
Small & 0.2 & Cohen, 1988 \\
Medium & 0.5 & Cohen, 1988 \\
Large & 0.8 & Cohen, 1988 \\
Very large & 1.2 & Sawilowsky, 2009 \\
Huge & 2 & Sawilowsky, 2009 \\
\hline
\end{tabular}

The formulas illustrated in Appendix were applied to calculate Cohen's $d$ with descriptive data given by the original studies. According to Ellis (2010), different studies could be compared to each other with the effect size. Two formulas were used to calculate effect sizes for studies with and without control groups. The ultimate means and standard deviations used in this meta-analysis were average value calculated by the authors.

\subsection{Effect Model}

Two statistical models can be adopted when performing a meta-analysis: fixed effect and random effect. Fixed-effect model does not concern with dispersion in the observed effects because it is assumed to reflect nothing more than sampling error, whereas in the random-effect model, the dispersion in effects is assumed to be real. In most cases, the usage of the model is determined according to the test result of heterogeneity: if $p>0.1$, it is suggested to employ the fixed-effect model since homogeneity is observed among the independent studies; if $p \leq 0.1$, it is suggested to employ the random-effect model (Zhang, 2015). Since the heterogeneity was observed in the present study $(p \leq 0.1)$, random-effect model was used in it.

\subsection{Research Synthesis}

Cohen's $d$ values were identified by calculating two contrastive means of dependent variables, between-group contrasts and within-group contrasts (pre-post Contrasts). Between-group contrasts involve 17 studies, which include both experimental groups and control groups. Other 4 studies without control groups were examined through pre-post contrasts. Table 3 and Table 4 show the aggregated effect sizes for group contrasts and for pre-post contrasts respectively. Twenty-one unique effect sizes (17 effect sizes for group contrasts and 4 effect sizes for pre-post contrasts) and a total sample size of 1,268 participants were included. The sample sizes of group contrasts ranged from 10 to $67(\mathrm{M}=31.88)$ for experimental groups and 10 to $139(\mathrm{M}=35.65)$ for control groups. The sample sizes of the pre-post contrasts ranged from 12 to $60(\mathrm{M}=30)$.

After all the descriptive statistics and the effect sizes were calculated, the data were then submitted to Stata (Version 14) to do meta-analysis.

Table 3. Aggregated effect sizes (group contrasts)

\begin{tabular}{lllll}
\hline & $N$ (total) & $N \exp$ & $N c$ & $d$ \\
\hline Alavi \& Keyvanshekouh (2012) & 38 & 20 & 18 & $1.25^{*}$ \\
Al-Homoud \& Schmitt (2009) & 65 & 45 & 20 & $0.52^{*}$ \\
Cha (2009) & 20 & 10 & 10 & 0.45 \\
Chang (2013) & 64 & 30 & 34 & -1.77 \\
Hamed (2014) & 36 & 18 & 18 & 4.56 \\
Jafarpour (2014) & 40 & 20 & 20 & 1.02 \\
Lee (2007) Study 1 & 141 & 65 & 76 & -0.77 \\
Lee (2007) Study 2 & 206 & 67 & 139 & 0.17 \\
\hline
\end{tabular}




\begin{tabular}{lllll}
\hline Rafatbakhsh \& Alavi (2013) & 33 & 15 & 18 & -0.13 \\
Rashtchi \& Pourmand (2014) & 60 & 30 & 30 & 0.58 \\
Rosszell (2007) & 40 & 20 & 20 & $1.06^{*}$ \\
Soltani (2011) & 80 & 40 & 40 & $1.45^{*}$ \\
Teng (2015) Study 1 & 52 & 26 & 26 & $4.77^{*}$ \\
Teng (2015) Study 2 & 46 & 23 & 23 & $2.58^{*}$ \\
Tiryaki \& Tütüniş (2012) & 100 & 50 & 50 & $5.18^{*}$ \\
Vaezi \& Nilforooshan (2013) & 60 & 30 & 30 & $1.96^{*}$ \\
Yamamoto (2011) & 67 & 33 & 34 & $0.59^{*}$ \\
\hline
\end{tabular}

Note. $\exp =$ experiment group. $c=$ control group.

*Indicates an averaged effect size within the study.

Table 4. Aggregated effect sizes (pre-post contrasts)

\begin{tabular}{lll}
\hline & $N \exp$ & $d$ \\
\hline Chang (2015) & 31 & $4.21^{*}$ \\
Kweon \& Kim (2008) & 12 & $1.68^{*}$ \\
Webb \& Chang (2015) & 60 & $1.24^{*}$ \\
Yamashita \& Kan (2010) & 17 & $0.67^{*}$ \\
\hline
\end{tabular}

Note. $\exp =$ experiment group.

*Indicates an averaged effect size within the study.

\section{Results}

\subsection{Features of the Data}

Table 5 demonstrates the research features of studies covered in this meta-analysis and the corresponding percentages. The majority of the participants were university students $(67 \%)$ followed by high school students $(19 \%)$.

Table 5. Research features

\begin{tabular}{llll}
\hline Features & & No. of studies & $\%$ \\
\hline Participants & 1. Junior high school students & 1 & 5 \\
& 2. High school students & 4 & 19 \\
& 3. University students & 14 & 67 \\
& 4. Adults & 1 & 5 \\
& 5. Children (elementary school or below) & 1 & 5 \\
Length of instruction & 1. One semester (less than 3 months) & 11 & 52 \\
& 2. Two semesters (from 3 months to 6 months) & 8 & 38 \\
Reading materials & 3. One year (from more than 6 months to 1 year) & 2 & 10 \\
& 1. Graded Readers & 18 & 86 \\
2. Story books & 6 & 29 \\
Treatment & 3. Reading Power & 2 & 10 \\
& 1. Book report & 15 & 71 \\
& 2. Comprehension questions & 3 & 14 \\
\hline
\end{tabular}




\begin{tabular}{llll}
\hline & 3. Dictionary usage & 7 & 33 \\
4. Vocabulary exercise & 8 & 38 \\
& 5. Vocabulary instruction & 4 & 19 \\
6. Others & 6 & 29 \\
Control group & 1. None (i.e., pre-post design) & 4 & 19 \\
& 2. One group & 15 & 71 \\
3. Two groups or more & 2 & 10 \\
Test use & 1. Same test version used in pre and post test & 12 & 57 \\
Test reliability & 2. Parallel version & 9 & 43 \\
& 1. Not reported & 12 & 57 \\
& 2. Reported (data based on the current study) & 5 & 24 \\
& 3. Reported (data cited from the test manual) & 4 & 19 \\
\hline
\end{tabular}

Note. $k=21$. All the percentages are rounded. The total numbers of studies adopting reading materials and treatment vary because some studies included more than one type of reading materials or treatments.

More than half of the studies had short-term instruction (less than 3 months) and $38 \%$ of the studies' instructions were between 3 months and 6 months. Only 2 studies were conducted for a period between 6 months and 1 year. However, studies conducted for more than 1 year were not included.

In terms of reading materials, Graded Readers $(86 \%)$ was most used among the 21 studies, whereas, story books and Reading Power were only used in 6 and 2 studies respectively. As regards extensive reading treatment concerning students' vocabulary acquisition, book report (71\%) was the top option, followed by vocabulary exercise (38\%), dictionary usage (33\%) and others (29\%) including MoodleReader and oral rendition of texts. On the contrary, vocabulary instruction (19\%) and comprehension questions $(14 \%)$ were the least popular. A number of $81 \%$ hade one or more control groups, while $19 \%$ failed to do so.

Over half of the studies administered pre-posttests whose versions were the same and $43 \%$ of the studies used parallel versions of tests. Only $24 \%$ of the studies report test reliability with data based on the current study, but $19 \%$ cited data from the tests manual.

\subsection{Publication Bias (Sensitivity Analysis)}

It is important to assess publication bias in meta-analysis because "literature reviews regarding support for a hypothesis can be biased if the original literature is contaminated by publication bias" (Rothstein et al., 2006). The most common way to present publication bias is the employment of a funnel plot which indicates a relationship between effect size and study precision. To measure study precision, choices including sample size, standard error and inverse variance of the effect size are available. However, Sterne and Egger (2001) conclude that standard error is the most recommendable based on the comparison they have made.

As Ioannidis (2007) claims, funnel plot can be drawn when there are at least 10 studies in the meta-analysis. Therefore, the funnel plot for pre-post contrast fails to be provided because the number of studies in pre-post contrasts is only four. Figure 1 shows the funnel plot for group contrasts, visually representing the possible publication bias. In the funnel plot, a relationship between standard errors plotted on the reversed y-axis and effect sizes (SMD) for each study plotted on the $\mathrm{x}$-axis is displayed. 


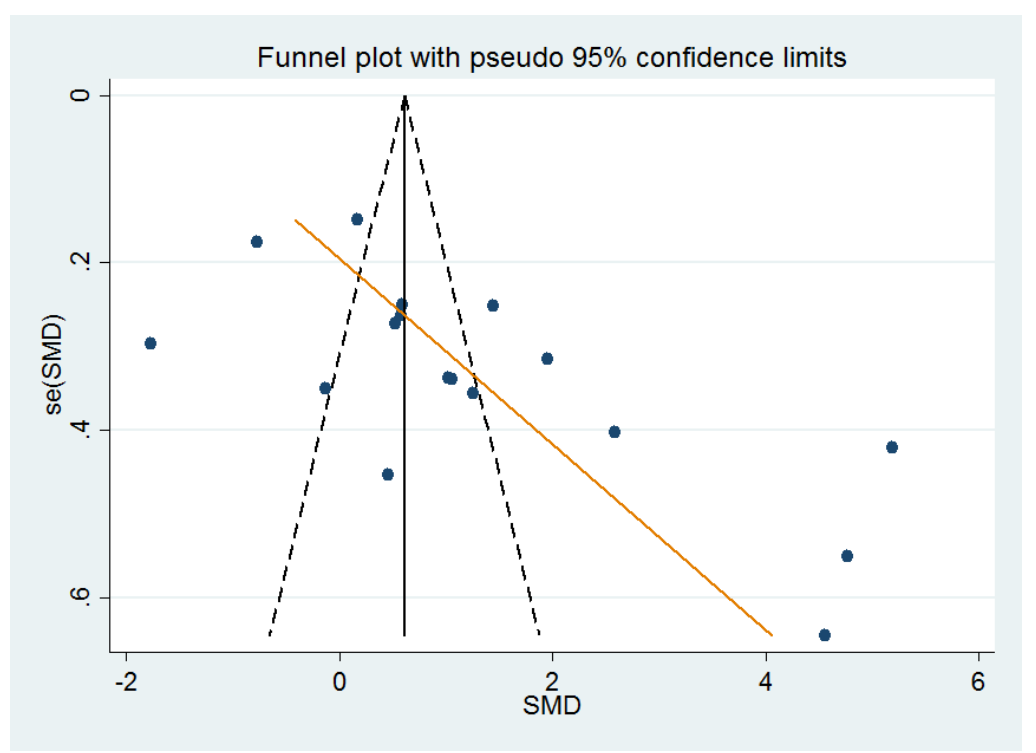

Figure 1. Funnel plot of group contrasts

It should be noted that the largest studies have the smallest standard errors, which is the reason why the largest studies are placed at the top of the graph, thus the y-axis must be reversed (standard error 0 at the top) (Sterne et al., 2004).

Because the accuracy of the effect will increase when the number of studies is large, smaller effects will be scattered widely at the bottom of the plot and larger effects will be distributed intensively in the center or top of the funnel plot. In addition, among many reasons that may cause the asymmetry of the funnel plot, the major one might be the uneven quality of the studies. Smaller and low-quality studies may trigger significant intervention because of their less precise data.

In Figure 1, the funnel plot presents an asymmetric inverted funnel, and the distribution is quite dispersed, therefore, the included studies may have publication bias. The reason might be that the research sizes included in this meta-analysis are relatively small. Therefore, more large-size studies should have been included in this meta-analysis. In addition, the data adopted in this meta-analysis is continuous and standardized mean difference (SMD) is used. There is no recommendable method to exam the asymmetry of the funnel plot, because the number of studies using continuous data and standardized mean difference is not big enough for reference (Zhang, 2015). Thus, the asymmetry of the funnel plot will not be further examined.

\subsection{Meta-Analysis}

To answer the first research question, the authors used Cohen's $d$ value to examine the overall effect size of extensive reading's effects on English vocabulary acquisition. The results of the group contrasts are illustrated in Table 6, including effect sizes, the number of studies, sample size, and confidence intervals.

Table 6. Overall meta-analysis results for group contrasts

\begin{tabular}{llllll}
\hline Group & Subgroup & $d$ & $k$ & $N$ & $C I$ (Low, High) \\
\hline Overall & & 1.32 & 17 & 1,148 & {$[0.62,2.02]$} \\
Participants & 1. Junior high school students & 0.58 & 1 & 60 & {$[0.06,1.09]$} \\
& 2. High school students & 0.82 & 2 & 60 & {$[0.28,1.35]$} \\
& 3. University students & 1.1 & 12 & 868 & {$[0.33,1.87]$} \\
& 4. Adults & 1.96 & 1 & 60 & {$[1.34,2.57]$} \\
& 5. Children (elementary school or below) & 5.18 & 1 & 100 & {$[4.36,6.01]$} \\
Length of instruction & 1. One semester (less than 3 months) & 2.1 & 9 & 607 & {$[0.83,3.37]$} \\
& 2. Two semesters [3 months, 6 months] & 0.56 & 7 & 335 & {$[-0.37,1.49]$} \\
\hline
\end{tabular}




\begin{tabular}{|c|c|c|c|c|c|}
\hline & 3. One year (6 months, 1 year] & 0.17 & 1 & 206 & {$[-0.12,0.46]$} \\
\hline \multirow[t]{3}{*}{ Reading materials } & 1. Graded Readers & 1.48 & 14 & 975 & {$[0.63,2.34]$} \\
\hline & 2. Story books & 0.62 & 5 & 419 & {$[0.06,1.17]$} \\
\hline & 3. Reading power & 0.5 & 2 & 85 & {$[0.05,0.96]$} \\
\hline \multirow[t]{6}{*}{ Treatment } & 1. Book report & 0.57 & 11 & 787 & {$[-0.07,1.21]$} \\
\hline & 2. Comprehension questions & 4.77 & 1 & 52 & {$[3.69,5.85]$} \\
\hline & 3. Dictionary usage & 1.3 & 5 & 221 & {$[0.35,2.24]$} \\
\hline & 4. Vocabulary exercise & 1.35 & 8 & 396 & {$[0.55,2.15]$} \\
\hline & 5. Vocabulary instruction & 1.46 & 4 & 346 & {$[-0.66,3.58]$} \\
\hline & 6. Others & 0.32 & 4 & 195 & {$[-1.38,2.03]$} \\
\hline \multirow[t]{2}{*}{ Test use } & 1. Same test version used in pre and post & 1.45 & 9 & 735 & {$[0.47,2.43]$} \\
\hline & 2. Parallel version & 1.18 & 8 & 413 & {$[0.08,2.29]$} \\
\hline \multirow[t]{3}{*}{ Test reliability } & 1. Not reported & 0.71 & 8 & 682 & {$[-0.38,1.79]$} \\
\hline & 2. Reported (data based on the current study) & 0.92 & 5 & 292 & {$[0.42,1.42]$} \\
\hline & 3. Reported (data cited from the test manual) & 3.18 & 4 & 174 & {$[1.41,4.96]$} \\
\hline
\end{tabular}

As is shown in Table 6, the overall confidence interval (CI) does not include 0, which means that the extensive reading has a very large effect on English vocabulary learning $(d=1.32)$, and experimental groups perform better than the control groups. In terms of the interpretation of the test of homogeneity, Higgins (2003) suggested that the bigger $I^{2}$ is, the higher the homogeneity is. The result $\left(p=0.00, d . f .=16, I^{2}=96.1 \%\right)$ of the homogeneity test indicates that homogeneity exists and it is quite large.

Furthermore, the overall effect size $(d=3.26)$ in Table 7 indicates that the effect of extensive reading in the pre-post contrasts is also very large and participants perform better in the posttests than in the pretests. This effect size is much larger than that in group contrasts $(d=1.32)$. As the result $\left(p=0.008, d . f .=3, I^{2}=22.2 \%\right)$ of the homogeneity test suggests, the homogeneity is slight and not statistically significant because $I^{2}$ is between $0 \%$ and $40 \%$.

Table 7. Overall meta-analysis results for pre-post contrasts

\begin{tabular}{llllll}
\hline Group & Subgroup & $d$ & $k$ & $N$ & $C I$ (Low, High) \\
\hline Overall & & 3.26 & 4 & 120 & {$[1.74,4.77]$} \\
Participants & 1. Junior high school students & - & - & - & - \\
& 2. High school students & 3.85 & 2 & 91 & {$[2.17,5.53]$} \\
& 3. University students & 0.71 & 2 & 29 & {$[-2.77,4.18]$} \\
& 4. Adults & - & - & - & - \\
& 5. Children (elementary school or below) & - & - & - & - \\
Length of instruction & 1. One semester (less than 3 months) & 4.19 & 2 & 43 & {$[2.41,5.97]$} \\
& 2. Two semesters [3 months, 6 months] & 0.67 & 1 & 17 & {$[-2.87,4.21]$} \\
& 3. One year (6 months, 1 year] & 1.24 & 1 & 60 & {$[-3.56,6.04]$} \\
Reading materials & 1. Graded Readers & 3.26 & 4 & 120 & {$[1.74,4.77]$} \\
& 2. Story books & 1.68 & 1 & 12 & {$[-16.68,20.04]$} \\
Treatment & 3. Reading power & - & - & - & - \\
& 1. Book report & 3.26 & 4 & 120 & {$[1.74,4.77]$} \\
& 2. Comprehension questions & 4.19 & 2 & 43 & {$[2.41,5.97]$} \\
& 3. Dictionary usage & 3.85 & 2 & 91 & {$[2.17,5.53]$} \\
\hline
\end{tabular}




\section{Vocabulary exercise}

5. Vocabulary instruction

6. Others

Test use
1. Same test version used in pre and post

2. Parallel version

$\begin{array}{llll}- & - & - & - \\ - & - & - & - \\ 3.85 & 2 & 91 & {[2.17,5.53]} \\ 0.89 & 3 & 89 & {[-1.93,3.71]} \\ 4.21 & 1 & 31 & {[2.42,6.01]}\end{array}$

\subsection{Moderator Variable Analysis}

Research question 2 and 3 are concerned with investigating systematic disparity in the effectiveness of extensive reading across age group, length, reading materials, treatment and test of instruction. To answer these two questions, effect sizes were calculated for coded subgroups (see Table 6 and Table 7).

First of all, five age group variables were investigated. Regarding group contrasts, all the confidence intervals do not include zero. The effect size for children indicates a huge effect $(d=5.18)$, followed by adults $(d=1.96)$, university students $(d=1.10)$, high school students $(d=0.82)$ and junior high school students $(d=0.58)$. For the pre-post contrasts, the effect size for university students includes zero. And there is a huge effect for high school students $(d=3.85)$.

In terms of the length of extensive reading instruction, effect sizes for two semesters and one year in the group contrasts include zero, while one semester $(d=2.10)$ has a significantly huge effect. Similarly, the confidence intervals for two semesters and one year in the pre-post contrasts include zero, while one semester $(d=4.19)$ has a huge effect size. Overall, the shorter the length of extensive reading instruction is, the larger effect size is.

Regarding reading materials in the group contrasts, a very large effect for Graded Readers $(d=1.48)$, and medium effects for story books $(d=0.62)$ and reading power $(d=0.50)$ are obtained. In the pre-post contrasts, confidence interval for story books includes zero. A huge effect for Graded Readers $(d=3.26)$ is obtained. Overall, Graded Readers is the most appropriate reading material for extensive reading instruction.

Concerning treatment in the group contrasts, the three confidence intervals for book report, vocabulary instruction and others include zero. Comprehension questions $(d=4.77)$ has huge effect size; dictionary usage $(d$ $=1.30)$ and vocabulary exercise $(d=1.35)$ have very large effect sizes. Likewise, in the pre-post contrasts, studies adopting book report $(d=3.26)$, comprehension questions $(d=4.19)$, dictionary usage $(d=3.85)$ and others $(d=3.85)$ produce huge effect sizes. Overall, comprehension questions are the most effective method in ER instruction, and followed by dictionary usage.

Furthermore, test use produces the following effects. In group contrasts, both studies using the same test version for pre-test and post-test $(d=1.45)$, and studies using parallel version $(d=1.18)$ produce very large effect sizes. However, in pre-post contrasts, the confidence interval for studies using the same test version include zero. And the effect size of studies using parallel version $(d=4.21)$ is much huger than the one for group contrasts.

Regarding the test reliability, the confidence interval for studies without reported test reliability include zero, while studies reporting reliability with data based on the current study $(d=0.92)$ yield large effect size and studies reporting reliability with cited ones $(d=3.18)$ produce huge effect size. Notice that all the four studies in pre-post contrasts do not report test reliability, so it is meaningless to display the results.

The Vocabulary Levels Tests (VLT) (Schmitt et al., 2001) were used most frequently $(\mathrm{n}=8$ ), followed by the Vocabulary Levels Test $(n=3)$. Among the remaining studies, 10 studies adopted other vocabulary tests created by former researchers, such as the Productive Vocabulary Levels Test (Laufer \& Nation, 1999) and Vocabulary Knowledge Scale (Wesche and Paribakht, 1996) and the others used general vocabulary knowledge tests designed by their own.

\section{Discussion}

\subsection{Overall Effect of Extensive Reading on Vocabulary Learning}

The first research question is concerned with the effect of extensive reading instruction. In the group contrasts $(d$ $=1.32$ ), students who received extensive reading instruction outperform students who did not to a large extent; similarly, in the pre-post contrasts $(d=3.26)$, students make a huge progress significantly in vocabulary learning after receiving extensive reading instruction. It should be noted that these huge effect sizes are consistent with the results of studies reviewed in this synthesis, which soundly confirms that extensive reading has unquestionably positive impact on students' English vocabulary acquisition to a huge extent. There is no 
negative effect because the effect sizes for pre-post contrasts ranged from 1.74 to 4.77 . However, it is suggested that its effect size $(d=3.26)$ should be interpreted cautiously since control groups were not included in the analysis.

\subsection{Learner's Age}

Although learner's age is not involved in the research questions, it is worthy to find out which age group benefits the most from extensive reading instruction on their vocabulary learning and how they are different. Surprisingly, extensive reading was found to be effective in all group contrasts of different ages, and the effect sizes for children $(d=5.18)$ and adults $(d=1.96)$ show to be huge. In the pre-post contrasts, no effect was found among university student while the effect size for high school student $(d=3.85)$ is quite huge, which might be caused by the small number of studies included. In terms of high school students and university students, two studies for each respectively were included. Junior high school students, children and adults only have one study respectively. In the group contrasts, the finding that children benefit the most is quite different from that of Nakanishi (2015), because Nakanishi didn't include children participants in his study. However, we should note the limitation of the study number $(k=1)$ of children, and further research is recommended. Among the remaining age groups, adults, followed by university students $(d=1.10)$, high school students $(d=0.82)$, junior high school students $(d=0.58)$, yield significant effect size, which may indicate that the older they are, the more effective extensive reading will be in promoting their acquisition of vocabulary. This finding is in line with Nakanishi's study, which concludes that extensive reading might be more beneficial for late learners because of their stronger analytical skills in understanding the reading contents. It should be noted that the numbers of studies for the participant categories are quite small except university students. It is strongly suggested that more research should be conducted to confirm this finding. There is no difference among groups as the overlapping confidence intervals indicate statistically.

\subsection{Length of Instruction}

The second research question is concerned with the length of extensive reading instruction. As the results indicate, one semester of extensive reading instruction for both group contrasts and pre-post contrasts yield huge effect sizes $(d=2.10$ and $d=4.19$ - respectively). Whereas, no effect was found for two-semesters and one-year instruction in both group contrasts and pre-post contrast. Therefore, two interesting results were revealed. One aspect is that one semester seems to be the most appropriate length of instruction period. The other is that shorter-term ER instruction can promote vocabulary learning better, which is contrary to the finding of Nakanishi (2015), i.e., the longer the instruction length is, the better the treatment will be. This finding is also different from the claim of Grabe (2009, p. 328), "reading extensively, when done consistently over a long period of time, leads to better reading comprehension as well as improved abilities in several other language areas". Based on Papagno's (1991) statement that phonological short-term memory contributes to foreign-language vocabulary learning, the reason for the results might be that shorter period of time for extensive reading instruction is suitable for participants to memorize certain amount of vocabulary. On the contrary, longer length of instruction may lead to quick forgetting. However, this hypothesis should be proved further by more studies.

\subsection{Reading Materials}

The last research question is concerned with the procedure of extensive reading instruction. Specifically, this meta-analysis tries to find out what the most effective reading material is and what the most effective education treatment is in terms of vocabulary learning through extensive reading. In the group contrasts, three categories of reading materials are reported to be effective. Graded Readers $(d=1.48)$ produces a very large effect, followed by story books $(d=0.62)$ and reading power $(d=0.50)$ both yielding medium effect. In the pre-post contrasts, only Graded Readers $(d=3.26)$ is found to produce a huge effect. The results indicate that Graded Readers is most suitable for participants to read among the three options for extensive reading instruction, which is consistent with the statement that Graded Readers are useful reading materials for students with a lower-intermediate level to improve the learning of vocabulary (e.g., Nation, 2001; Nation, 2009). Compared with Graded Readers, story books and reading power are relatively less effective, probably because the contents are not simplified or the story books are not as strictly classified as Graded Readers. It is recommended that future studies should investigate the effect of story books and reading power on vocabulary learning in extensive reading instruction.

\subsection{Treatment}

Another crucial factor influencing the effect of extensive reading on vocabulary learning is the education treatment or method. Three categories, book report, vocabulary instruction and others, include the confidence 
interval of zero for group contrasts, while the effect size for comprehension questions $(d=4.77)$ produces a huge effect, followed by dictionary usage $(d=1.30)$ and vocabulary exercise $(d=1.35)$ which have huge effects. With a relatively bigger number of studies included in this synthesis, vocabulary exercise is highly recommendable including sentence-making and vocabulary worksheet. Muncie (2002) pointed out that writing in context, with attention to vocabulary use, is a tool for general second language improvement. Therefore, as one of the forms of writing, sentence making helps participants to remember not only the form of the words but also the meaning in specific contexts. Other vocabulary exercises provide participants with opportunities to meet the unfamiliar words repeatedly. In addition, with the instructor's permission and encouragement of dictionary usage, participants are more likely to understand the unknown word immediately, which helps participants read more confidently and smoothly. However, in some primary studies, dictionary is not allowed to be used because participants are encouraged to guess the meanings according to the contexts instead of reading intensively.

In the pre-post contrasts, comprehension questions $(d=4.19)$ yields a huge effect, followed by dictionary usage and others, which have the same huge effects $(d=3.85)$. It should be noted that two methods contained in others, MoodleReader and oral rendition, are reported to be conductive to student's vocabulary learning. Robb (2005) argues that MoodleReader is also one of the extensive reading promoting programs which allows students do randomized vocabulary quizzes on Graded Readers online. As one of the audio-assisted reading methods, oral rendition provides participants with opportunities to learn both written and spoken forms of a word (Chang, 2013). Moreover, book report also reveals its positive effect, which involves reading journals, reading log and book summary. It thus reflects that unfamiliar words encountered in extensive reading are more likely to be acquired through writing the summary of the plot and reflection of the book.

\section{Conclusion}

As overall strength of extensive reading produced a very big effect size on group contrasts $(d=1.32)$ and a huge effect size on pre-post contrasts $(d=3.26)$, we can draw a firm conclusion that extensive reading has a significantly large effect on English vocabulary learning. With respect to instruction specifications, it is suggested that teachers should adopt Graded Readers as extensive reading materials and apply both comprehension questions and vocabulary exercise as teaching methods to promote the vocabulary learning of EFL learners. One semester (less than three months) is the most appropriate length of extensive reading instruction for vocabulary learning. Furthermore, extensive reading performs better in helping students memorizing vocabulary when the related instruction lasts shorter. Regarding test use and test reliability, results of studies are more reliable if the same test version is used in the pre-test and post-test and the reliability is reported by citing the data from the test manual.

The authors hope this study may provide helpful insights for extensive reading research with the issues coming up in this meta-analysis. Teachers tend to have more new and effective options to promote student's vocabulary acquisition. Moreover, further studies in the future are encouraged to be done to investigate the specific reasons for the interesting findings revealed in this meta-analysis.

In the studies covered in this meta-analysis, most participants are university students, followed by children. The length of the studies is mostly short term (less than 6 months). Therefore, it is suggested that there should be more research with other age groups over one year of instruction. Furthermore, more studies of large sample size regarding the effects of extensive reading on vocabulary should be included in future meta-analysis. It is more comprehensive and conductive to adopt meta-analysis as the methodology of research synthesis than any independent study due to its revealing of the research tendency in the past and the research direction in the future.

\section{References}

Alahirsh, H. (2014). Exploring the effectiveness of extensive reading on incidental vocabulary acquisition by EFL learners: An experimental case study in a Libyan University (Doctoral dissertation, University of Nottingham).

Alavi, S., \& Keyvanshekouh, A. (2012). Using the MoodleReader as an extensive reading tool and its effect on Iranian EFL students' incidental vocabulary learning. English Language Teaching, 5(6), 135-145. https://doi.org/10.5539/elt.v5n6p135

Al-Homoud, F. A., \& Alsalloum, M. S. (2012). The effects of extensive reading on the breadth and depth of vocabulary knowledge and reading speed. In Extensive Reading World Congress Proceedings, 1(6), 5-67.

Al-Homoud, F., \& Schmitt, N. (2009). Extensive reading in a challenging environment: A comparison of extensive and intensive reading approaches in Saudi Arabia. Language Teaching Research, 13(4), 383-401. 
https://doi.org/10.1177/1362168809341508

Beglar, D., Hunt, A., \& Kite, Y. (2012). The effect of pleasure reading on Japanese university EFL learners' reading rates. Language Learning, 62(3), 665-703. https://doi.org/10.1111/j.1467-9922.2011.00651.x

Biemiller, A. (2005). Size and sequence in vocabulary development: Implications for choosing words for primary grade vocabulary instruction.

Cha, J. E. (2009). The effects of extensive reading on enhancing vocational high school students' L2 vocabulary \& reading rates. English Teaching, 64(3), 3-30. https://doi.org/10.15858/engtea.64.3.200909.3

Chang, A. C. (2015). An investigation of different text levels on L2 learners' vocabulary learning rates in an extensive reading program. Vocabulary Learning and Instruction, 47. 47-57.

Chang, Anna C-S. (2013). The effect of audio-assisted extensive reading on vocabulary learning and retention. Extensive Reading World Congress, 299-310.

Chin-Neng, C. H. E. N., Shu-Chu, C. H. E. N., Shu-Hui, E. C., \& Shyh-Chyi, W. E. Y. (2013). The effects of extensive reading via e-books on tertiary level EFL students' reading attitude, reading comprehension and vocabulary. TOJET: The Turkish Online Journal of Educational Technology, 12(2).

Cobb, T. (2007). Computing the vocabulary demands of L2 reading.

Cohen, J. (1988). Statistical power for the behavioral sciences. Hillside.

Day, R. R. (2004). Extensive reading activities for teaching language. Ernst Klett Sprachen.

Ellis, P. D. (2010). The essential guide to effect sizes: Statistical power, meta-analysis, and the interpretation of research results (pp. 10-11). Cambridge University Press. https://doi.org/10.1017/CBO9780511761676

Glass, G. V. (1976). Primary, secondary, and meta-analysis of research. Educational researcher, 5(10), 3-8. https://doi.org/10.3102/0013189X005010003

Grabe, W. (2009). Reading in a second language: Moving from theory to practice (p. 328). Ernst Klett Sprachen.

Higgins, J. P., Thompson, S. G., Deeks, J. J., \& Altman, D. G. (2003). Measuring inconsistency in meta-analyses. BMJ: British Medical Journal, 327(7414), 557. https://doi.org/10.1136/bmj.327.7414.557

Hong, S. (2014). Extensive reading in a second language: Literature review and pedagogical implications (Doctoral dissertation).

Ioannidis, J. P., \& Trikalinos, T. A. (2007). The appropriateness of asymmetry tests for publication bias in meta-analyses: A large survey. Canadian Medical Association Journal, 176(8), 1091-1096. https://doi.org/10.1503/cmaj.060410

Ismael, H. I., Mohamed, H. A., \& Mohammed, M. A. (2017). Investigating the role of extensive reading in developing student speaking skill (Doctoral dissertation, Sudan University of Science and Technology).

Jafarpour, M. (2014). The effect of incorporating the extensive reading approach into vocabulary instruction on learners' lexical depth in an EFL context. Advances in Language and Literary Studies, 5(3), 162-169. https://doi.org/10.7575/aiac.alls.v.5n.3p.162

Krashen, S. (1989). We acquire vocabulary and spelling by reading: Additional evidence for the input hypothesis. The modern language journal, 73(4), 440-464. https://doi.org/10.1111/j.1540-4781.1989.tb05325.x

Kweon, S. O., \& Kim, H. R. (2008). Beyond raw frequency: Incidental vocabulary acquisition in extensive reading. Reading in a foreign language, 20(2), 191-215.

Laufer, B., \& Nation, P. (1999). A vocabulary-size test of controlled productive ability. Language testing, 16(1), 33-51. https://doi.org/10.1177/026553229901600103

Lee, S. Y. (2007). Revelations from three consecutive studies on extensive reading. RELC Journal, 38(2), 150-170. https://doi.org/10.1177/0033688207079730

Light, R., \& Pillemer, D. B. (1984). Summing up: The science of reviewing research. Harvard University Press.

Lin, L. F. (2010). Senior high school students' reading comprehension of graded readers. Journal of Language Teaching and Research, 1(1), 20-28. https://doi.org/10.4304/j1tr.1.1.20-28

Lipsey, M. W., \& Wilson, D. B. (2001). Practical meta-analysis. Sage Publications, Inc.

Muncie, J. (2002). Process writing and vocabulary development: Comparing lexical frequency profiles across drafts. System, 30(2), 225-235. https://doi.org/10.1016/S0346-251X(02)00006-4 
Nagy, W. E., \& Scott, J. A. (2000). Vocabulary processes. Handbook of reading research, 3, 269-284.

Nakanishi, T. (2015). A meta-analysis of extensive reading research. Tesol Quarterly, 49(1), 6-37. https://doi.org/10.1002/tesq.157

Nation, I. S. P. (2001). Learning vocabulary in Another Language. Cambridge University Press. https://doi.org/10.1017/CBO9781139524759

Nation, I. S. P. (2009). Teaching ESL/EFL reading and writing. Routledge.

National Institute of Child Health and Human Development (2000). Report of the National Reading Panel. Teaching children to read: An evidence - based assessment of the scientific research literature on reading and its implications for reading instruction (NIH Publication No. 00 4769), Washington, DC: U.S. Government Printing Office.

Palmer, H. E. (1964). The principles of language-study (p. 111). Oxford University Press.

Papagno, C., Valentine, T., \& Baddeley, A. (1991). Phonological short-term memory and foreign-language vocabulary learning. Journal of Memory and Language, 30(3), 331-347. https://doi.org/10.1016/0749-596X(91)90040-Q

Rafatbakhsh, E., \& Alavi, S. (2013). The impact of computerized and paper-based "whodunits" as extensive reading materials on Iranian EFL learners' incidental vocabulary learning. Extensive Reading World Congress 2. (pp. 284-298).

Rashtchi, M., \& Pourmand, S. (2014). Controlled extensive reading and vocabulary knowledge: Let's move towards autonomous learning in EFL contexts. International Journal of English and Education, 3(2), 132-146.

Rezaee, A. A., \& Nourzadeh, S. (2011). Does extensive reading improve EFL learners' processing ability? Theory and practice in language studies, 1(9), 1167-1175. https://doi.org/10.4304/tpls.1.9.1167-1175

Ricahrds, J. C., \& Schmidt, R. (2002). Longman Dictionary of Language Teaching and Applied Linguistics (3rd ed.).

Robb, T. N. (2005). Outline of MoodleReader features. Retrieved December 10, 2010, from http://moodlereader.org $/ \mathrm{moodle} / \mathrm{mod} /$ resource $/$ view.php?inpopup=true \&id=3521

Rodrigo, V., Krashen, S., \& Gribbons, B. (2004). The effectiveness of two comprehensible-input approaches to foreign language instruction at the intermediate level. System, 32(1), 53-60. https://doi.org/10.1016/j.system.2003.08.003

Rosszell, H. R. (2007). Extensive reading and intensive vocabulary study in a Japanese university. Temple University.

Rothstein, H. R., Sutton, A. J., \& Borenstein, M. (Eds.). (2006). Publication bias in meta-analysis: Prevention, assessment and adjustments. John Wiley \& Sons.

Sawilowsky, S. S. (2009). New effect size rules of thumb. Journal of Modern Applied Statistical Methods, 8(2), 467-474. https://doi.org/10.22237/jmasm/1257035100

Schmitt, N., Schmitt, D., \& Clapham, C. (2001). Developing and exploring the behaviour of two new versions of the vocabulary levels test. Language testing, 18(1), 55-88. https://doi.org/10.1177/026553220101800103

Soltani, R. (2011). Extensive reading: A stimulant to improve vocabulary knowledge. Studies in literature and language, 2(3), 161-167. h

Stahl, S. A. (2005). Four problems with teaching word meanings. Teaching and learning vocabulary: Bringing research to practice, $95-114$.

Sterne, J. A., \& Harbord, R. M. (2004). Funnel plots in meta-analysis. Stata Journal, 4, 127-141.

Sterne, J. A., \& Egger, M. (2001). Funnel plots for detecting bias in meta-analysis: guidelines on choice of axis. Journal of clinical epidemiology, 54(10), 1046-1055. https://doi.org/10.1016/S0895-4356(01)00377-8

Suk, N. (2017). The effects of extensive reading on reading comprehension, reading rate, and vocabulary acquisition. Reading Research Quarterly, 52(1), 73-89. https://doi.org/10.1002/rrq.152

Tabata-Sandom, M. (2017). L2 Japanese learners' responses to translation, speed reading, and 'pleasure reading' as a form of extensive reading. Reading in a Foreign Language, 29(1), 113.

Tan, D. A. L. (2016). Investigating guided extensive reading and vocabulary knowledge performance among 
remedial ESL learners in a public university in Malaysia (Doctoral dissertation, University Sains Malaysia).

Teng, F. (2015). Extensive reading plus explicit vocabulary exercises: Is it better than extensive reading-only? Malaysian Journal of ELT Research, 11(2), 82-101.

Teng, F. (2015). The effectiveness of extensive reading on EFL learners' vocabulary learning: Incidental versus intentional learning. BELT-Brazilian English Language Teaching Journal, 6(1), 66-80. https://doi.org/10.15448/2178-3640.2015.1.20033

Tiryaki, Z. M., \& Tütüniş, B. (2012). The role of extensive reading on vocabulary. ELT Research Journal, 1(4), 209-215.

Vaezi, R., \& Nilforooshan, S. (2013). The effect of using Moodle Reader as an extensive reading tool on learners' awareness of affective dimensions of deep vocabulary knowledge. Mediterranean Journal of Social Sciences, 353.

Waring, R. (2003). At what rate do learners learn and retain new vocabulary from reading a graded reader? Reading in a Foreign language, 15(2), 130.

Webb, S., \& Chang, A. C. S. (2015). How does prior word knowledge affect vocabulary learning progress in an extensive reading program? Studies in Second Language Acquisition, 37(4), 1-25. https://doi.org/10.1017/S0272263114000606

Wesche, M., \& Paribakht, T. S. (1996). Assessing second language vocabulary knowledge: Depth versus breadth. Canadian Modern Language Review, 53(1), 13-40.

Wijaya, H. P. S. (2013). Extensive reading program: Its impacts on student's vocabulary size and reading comprehension (Doctoral dissertation, Petra Christian University).

Yamamoto, Y. (2011). Bridging the gap between receptive and productive vocabulary size through extensive reading. The Reading Matrix, 11(3), 226-242.

Yamashita, J., \& Kan, K. N. (2010). Examining effects of L2 extensive reading in the cognitive and affective domains. Applied Linguistics, Global and Local, 375-386.

Zhang, T. S. (2015). Advanced meta-analysis methods: Based on Stata (p. 36). Fudan University Press.

\section{Appendix}

Calculation of effect sizes

The following formula is used for group contrasts:

$$
\text { Cohen's } d=\left(M_{1}-M_{2}\right) / S_{\text {pooled }}
$$

Note. $M_{1}$ is the mean of posttest of experimental group, $M_{2}$ is the mean of posttest of control group, and Spooled is average population standard deviation.

The following formula is used for pre-post contrasts (Lipsey \& Wilson, 2001):

$$
E S=\left(X_{T 2}-X_{T 1}\right) / S_{p}
$$

Note. $X_{T 2}$ is the mean of post-test, $X_{T 1}$ is the mean of pre-test, and $S_{p}$ is the pooled standard deviation of the pre-test and post-test scores. The pooled standard deviations for the two contrasts are the average of two standard deviations.

\section{Copyrights}

Copyright for this article is retained by the author(s), with first publication rights granted to the journal.

This is an open-access article distributed under the terms and conditions of the Creative Commons Attribution license (http://creativecommons.org/licenses/by/4.0/). 